\title{
TESTIMONIO DIGITAL
}

\author{
DIGITAL TESTIMONY
}

\section{AUGUSTO LUIS PICCON}

\section{RESUMEN}

Este trabajo parte de una base, la cual no hace falta transitar nuevamente, y la da por supuesta, esto es, repetir por un lado la necesidad de adaptarnos como notarios a un nuevo soporte; así como el tabelión tuvo que pasar de la tablita de arcilla encerada que le dio su nombre, al uso del pergamino y luego del papel, nosotros tendremos que adaptarnos al uso del documento digital, o sea al instrumento que tiene un soporte metal-magnético. Tampoco adentrarnos en el tema de la firma digital, su historia, el procedimiento para llegar a la misma, etc. No queremos perder el tiempo en estos temas que tan bien han desarrollado otros autores en tantísimos trabajos para avanzar en un tema específico, en relación al documento digital, esto es la confección de un testimonio digital.

Circunscribimos el planteo solo en relación al testimonio de la escritura, y no en relación al protocolo, pues creemos que si bien es necesario adaptarnos a las nuevas tecnologías, los cambios tienen que ser paulatinos. Necesariamente el cambio lleva una primera etapa de experimentación, de error y corrección, de conocimiento y manejo del tema, y principalmente porque el cambió no es bueno por el cambio mismo sino en base a fundamentos serios que dan lugar al mismo. Vemos muy claramente en este mundo que se ha revolucionado en el sector comunicacional, que es necesario contar con un documento apto para ser transmitido, de un lugar a otro con la inmediatez que nos dan la nuevas tecnologías y con las ventajas de contar con el pleno valor probatorio (tiene que salir a la luz las ventajas de que este documento digital sea público y no privado), pero no hay necesidad de dejar de lado el respaldo matriz y toda la seguridad que brinda. Todavía no se ven claramente las ventajas de un protocolo digital, quizás dentro de unos años, surjan estas ventajas, o quizás haya sistemas mas seguros en formato digital que en soporte papel, y debamos cambiar, pero aún no se ve este como el momento de hacerlo.

\section{ABSTRACT}

This work starts from a base, which is not necessary to travel again, and takes it for granted, that is, repeating on the one hand the need to adapt as notaries to a new support; Just as the tabelion had to go from the waxed clay board that gave it its name, to the use of the parchment and then of the paper, we will have to adapt to the use of the digital document, that is, the instrument that has a metal-magnetic support. Nor do we get into the subject of the digital signature, its history, the procedure to reach it, etc. We 
do not want to waste time on these issues that other authors have developed so well in so many works to advance a specific topic, in relation to the digital document, this is the preparation of a digital testimony.

We circumscribe the statement only in relation to the testimony of writing, and not in relation to the protocol, because we believe that while it is necessary to adapt to new technologies, the changes have to be gradual. Necessarily the change takes a first stage of experimentation, of error and correction, of knowledge and handling of the subject, and mainly because the change is not good for the change itself but based on serious foundations that give rise to it. We see very clearly in this world that has been revolutionized in the communication sector, that it is necessary to have a document capable of being transmitted, from one place to another with the immediacy that new technologies give us and with the advantages of having the full probative value (the advantages of this digital document being public and not private) have to come to light, but there is no need to set aside the matrix support and all the security it provides. The advantages of a digital protocol are still not clearly seen, perhaps in a few years, these advantages arise, or perhaps there are more secure systems in digital format than in paper format, and we must change, but this is not yet seen as the moment of doing it..

PALABRAS CLAVES: Testimonios - Copias.

KEYWORDS: Testimony - Copy.

SUMARIO: Soporte. Especificamente el soporte digital en el ámbito nacional. Especificamente el soporte digital en el ámbito provincial. Primero y sucesivos testimonios . Las hojas de papel sellado. Notas Marginales en relación a los testimonios. Testimonio como instrumento público. Segundos y sucesivos testimonios de escrituras donde surgen obligaciones pendientes. Integración al SIDANO. Conclusiones.

\section{TESTIMONIOS Y COPIAS}

A la par de los documentos originales (que nosotros llamamos generalmente matrices) que "se producen como resultado directo e inmediato de las facultades fedantes del notario, en asuntos de su competencia; los que recogen con fe pública originaria los hechos autenticados, percibidos sensorialmente y narrados con sujeción a los principios de evidencia y coetaneidad"1 existen otros instrumentos que llamamos genéricamente reproducciones "que se caracterizan... por tener fe transcriptiva o derivativa. Sólo se producen frente a la existencia física de otro documento, que es la causa constitutiva de su ser. En las copias o reproducciones hay algunos elementos genuinos, pues el soporte material no es el mismo del original ... Tienen corporalidad y formas extrínsecas propias, pero su contenido ideológico importa un transvasamiento del documento original. No se crean coetáneamente a los hechos autenticados (contenido) sino como trasuntos o traslados de otros. Representan al hecho documento y no al hecho natural o humano, que recogen aquéllos, en las múltiples maneras en que pueden acaecer."”

1 PELOSI, Carlos A. "El Documento Notarial” Ed. Astrea, $3^{\circ}$ reimpresión Bs As 1997, Pag 245.

2 PELOSI, Carlos A. "El Documento Notarial” Ed. Astrea, $3^{\circ}$ reimpresión Bs As 1997, Pag 245. 
Existe una terminología no muy bien depurada en los ordenamientos legales vigentes para hablar de estas reproducciones y que pueden dar lugar a confusión, el Código de Vélez hablaba de copia simplemente, y así reconocía el carácter de instrumento público a las escrituras hechas por los escribanos en sus libros de protocolo ... y a las copias sacadas en la forma que prescribe la ley Art 979 inc $1^{\circ}$, y el artículo 1010 determinaba que la copia hace fe como la matriz. Esta copia a la que se refería el código de Vélez es una reproducción literal del original, pero realizada de acuerdo a las normas establecidas para ello, que son dadas por el ordenamiento provincial. Pero la mayoría de los ordenamientos provinciales no hablan de copias sino de testimonios, esta terminología que es común ya en la jerga notarial viene, según Pelosi, de la "simplificación de "copia testimoniada" que se utilizó en determinado momento... debido a que lleva al final atestación sobre su fidelidad y procedencia." ${ }^{3}$ Si bien a Pelosi no le gusta esta terminología, es la que se terminó imponiendo en el tráfico, y así el nuevo Código nos habla de "copia o testimonio" tanto cuando determina que es instrumento público y su pleno valor probatorio (art 299) como cuando regula la expedición de ellas (art 308). Entendemos que es mejor hablar de testimonio pues ya está bastante arraigada en nuestro medio y es para diferenciarla de la simple copia, que no lleva exigencia alguna, solo a los efectos de dar a conocer la existencia de un instrumento matriz ${ }^{4}$ y sin valor legal alguno, no originando nota en la matríz ni llevan clausula final de suscripción, pudiendo ser firmadas o no por el escribano5. Así es como dice Ventura "el primero, segundo o ulterior testimonio es aquel que cumple con los requisitos legales y que tiene valor de instrumento público (art. 289, inc. a, del CCCN), por lo que también se le confiere el valor ejecutivo" en cambio la copia simple "...aunque estuviere certificada, ella no genera acción, porque no prueba sobre el contenido del acto, sino solo sobre la existencia del instrumento copiado" $\mathrm{Y}$ el ejemplo típico, que no trae su trabajo pero que daba en clase, para que podamos ver esto del valor ejecutivo, era el de la entrada al cine y la copia certificada de esta, solo con la primera podremos entrar a ver la película, y no con la segunda, aunque probemos que ella existe, no podremos ejercer nuestro derecho, y esto es un punto importante a tener en cuenta a los efectos de entender la importancia de generar un testimonio u otros testimonios.

\section{SOPORTE}

Tendríamos que analizar ahora que dice la ley con relación al soporte en que debe expedirse esta copia o testimonio.

Antes el código de Vélez, no vislumbró posibilidad alguna de algún otro soporte para trasladar el contenido de una escritura, pero el código Civil y Comercial de la Nación, trabajó en otro marco, o sea ya con la ley de firma digital en vigencia (ley 25506, sancionada el día 14 de Noviembre de 2001) y se ve claramente la intención del legislador de dejar abierta la vía para que las leyes locales reglamentaran la posibilidad de habilitar nuevas posibilidades de soporte, es más, ni siquiera se refirió específicamente al soporte digital, sino a cualquier tipo de soporte, queriendo ser así una normativa amplia y preparada para futuros avances que aún hoy siquiera imaginamos.

\footnotetext{
3 PELOSI, Carlos A. “El Documento Notarial” Ed. Astrea, $3^{\circ}$ reimpresión Bs As 1997, Pag 247.

4 GATTARI Carlos Nicolas, “MANUAL DE DERECHO NOTARIAL”, Editorial Depalma, Buenos Aires 1988, pág 185.

5 GONZALEZ, Carlos Emerito, “Derecho Notarial”, Ed La Ley, Bs As 1971, Pág 497.

6 VENTURA, Gabriel B, “Testimonios y Copias en el Nuevo Código Civil y Comercial de la Nación”, en la página web de la Academia Nacional de Derechos y Ciencias Sociales de Córdoba, http://www.acaderc.org.ar.
} 
El art 308 nos dice específicamente "El escribano debe dar copia o testimonio de la escritura a las partes. Ese instrumento puede ser obtenido por cualquier medio de reproducción que asegure su permanencia indeleble”

La ley ha sido muy abierta en cuando al soporte como ya dijimos, puede ser cualquiera que nos imaginemos hoy, pero también cualquier otro que nos imaginemos el día de mañana, y que hoy ni remotamente se nos ocurre. Sin embargo pone una condición, el medio utilizado debe asegurar su permanencia indeleble.

No son dos requisitos o sea por un lado la permanencia y por otro lado la indelebilidad, sino que debemos entender este requisito como una exigencia de que mientras dure no pueda ser modificado. Esto debe ser entendido así, porque la permanencia por si sola de un testimonio en cuanto es tal, o sea como una reproducción de la matriz que es la destinada a perdurar (con procedimientos especiales para su conservación) sería un contra sentido. O sea el documento que tiene como su requisito la conservación y permanencia es la escritura matriz, el protocolo, y por ello todos los recaudos para su confección, encuadernación, su guarda. Pero el testimonio no tiene como condición esencial su permanencia en el tiempo, tanto es así que está previsto el nuevo otorgamiento de reproducciones de esa matriz. El testimonio está concebido para salir al mundo, sufrir los avatares de esta circulación, y perder la existencia en ello.

Por otro lado la palabra indeleble, podemos leer que se utiliza para calificar a lo que resulta imposible de eliminar o quitar (definición de la Real Academia Española y es un concepto que procede del vocablo latino indelebilis). Es muy utilizado como adjetivo en relación a ciertos tipos de tintas. Hoy podemos comprar un marcador con tinta indeleble. Pero tengamos en cuenta que la tinta indeleble, tiene ciertas condiciones en relación a ciertos soportes, así puedo escribir sobre un vidrio sin que se borre fácilmente, pero la otra tinta que se borra sobre el vidrio fácilmente, no es fácil de borrar sobre papel, y por lo tanto en relación a ese soporte será indeleble. Aquí no solo vamos a cambiar de soporte, sino también vamos a dejar de lado las tintas. Pero lo más importante a destacar es que la ley no ha utilizado la palabra en este sentido, pues algo imposible de eliminar es algo permanente, y ¿para qué, la ley va utilizar dos palabras que digan lo mismo en la frase?.

La ley, lo que entiendo quiere, es que ese soporte asegure mientras dure, mientras permanezca, mientras dure su existencia, que no sea adulterable, que no se pueda modificar su contenido, conserve como decimos nosotros la integridad documental. Justamente el documento firmado digitalmente tiene a estas como una de sus características, ya que al ser encriptado con el sistema de doble clave no puede ser modificado?.

\section{Especificamente el soporte digital en el ámbito nacional}

El Código Civil y Comercial de la Nación no dictó el art 308 en forma aislada, lo hizo en primer lugar en un marco legal, porque entre las leyes especiales que no fueron derogadas se encuentra la ley 25506, hoy modificada por la ley 27446 , en que no solo se le da cabida en nuestro ordenamiento legal al documento digital (art 6), sino que además

\footnotetext{
7 La firma digital reconoce las siguientes csrecteristicas: • Autoría: Permite determinar con suficiente certeza la identidad del autor del documento que lleva dicha firma. • Integridad: La información es completa. • Inalterabilidad: Puede detectarse si la información ha sido modificada. BIBIANA, Luz Clara "Ley de Firma Digital Comentada", Editorial Jurídica Nova Tesis, Rosario 2006.
} 
permite trasvasar el contenido de otros documentos en otro soporte ${ }^{8}$, al soporte digital. Por lo tanto puede haber un documento digital, que no sea el que muestre el acto o hecho jurídico, sino que sea un documento de segundo grado, que nos muestra el documento de primer grado donde se encuentra el acto o hecho constatado. Así el art 11 nos dice "Los documentos electrónicos firmados digitalmente y los reproducidos en formato digital firmados digitalmente a partir de originales de primera generación en cualquier otro soporte, también serán considerados originales y poseen, como consecuencia de ello, valor probatorio como tales, según los procedimientos que determine la reglamentación"

Por lo tanto queda claro que en nuestra normativa nacional, está establecida perfectamente la posibilidad de realizar el testimonio de una escritura en soporte digital.

\section{Especificamente el soporte digital en el ámbito provincial}

Veamos ahora la situación del testimonio en cuanto a la legislación provincial, ya que la ley 4183 que data del año 1948 no ha sido modificada recientemente. Lo primero que uno pensaría es que no está adaptada para dar cabida al testimonio en soporte digital. Pero el legislador, tuvo la imaginación suficiente para ya en ese año darse cuenta que había que dejar lugar a futuros cambios tecnológicos que en ese momento no eran pensados, y así el art 67 de nuestra ley provincial no solo recepta la posibilidad de reproducción a través de fotocopias, las cuales habían sido creadas en 1931 (la xerografía) sino que además deja abierta posibilidad de realizar la reproducción del protocolo por otros mecanismos con la única condición de que sean aceptados por el Tribunal de Disciplina Notarial, o sea conociendo lo difícil que es a veces el cambio de una ley cuando simplemente no es para cambiar algo tan profundo e importante, sino para dar cabida al simple paso del tiempo, en las tecnologías que nos acompañan.

Artículo 67․- Los testimonios que expidan los escribanos podrán ser extendidos a mano o a máquina, en la forma y condiciones que se detallan en los arts. 52- y 53 de la ley, para la redacción del protocolo. También podrán ser obtenidos y otorgados por los sistemas de reproducción en fotocopia u otros similares que autorizare el Tribunal de Disciplina Notarial, en cuyo caso la constancia de si se trata del primero, segundo o sucesivos testimonios a que se refiere el art. $62^{\circ}$ se colocará al final.

Por esa razón estamos en una mejor situación que otras provincias, y en este aspecto solo tenemos simplemente que solicitar al Tribunal de Disciplina una Acordada que le de cabida.

\section{Primero y sucesivos testimonios}

Según rezaba el antiguo Art 1006 el escribano debe dar a las partes que lo pidiesen copia autorizada de la escritura que hubieren otorgado, hoy el 308CCC dice simplemente que el escribano deber dar copia o testimonio de la escritura a las partes, sin mencionar el "que la pidiesen", pero evidentemente tienen que solicitarlo, por el principio de rogación. O sea que el escribano tiene la obligación cuando las partes lo solicitaran de entregar este testimonio, tal cual como lo expresa la ley provincial (art 60 ley 4183).

8 María Alejandra ASTUENA, Virginia BENFIELD, Gustavo A. DARCHUK, Roberto MIGNOLO, José María LORENZO, Mariano LOZANO, Pablo SUKAREVICIUS, Elsa ROSIN de ALLENDE y Luciana TORRES DUBECQ, "Incorporación de Documentación Habilitante Digital al Protocolo", trabajo presentado en las Jornadas Nacionales del Notariado, Bariloche 2018. 
"El derecho de obtener copia se limita a quienes hayan sido partes, por tanto cualquier otra persona que por algún motivo la requiera deberá obtenerla por decisión judicial. Así como el escribano está obligado a dar copia a las partes, lo está de no darla a quien no reviste ese carácter ya que el carácter de instrumento público de la escritura no significa que el contenido de ésta deba ser divulgado. Por el contrario, se encuentra protegido por el secreto profesional. Por tanto, salvo orden judicial, el escribano debe abstenerse de entregar a terceros ningún tipo de reproducciones del acto."’.

Sin embargo, Orelle nos hace ver que no hay una línea divisoria tan clara entre parte y tercero, "la tajante división entre partes y terceros, cede luego cuando se profundiza el estudio, ante la consideración de innumerables matices que la vida social exhibe."10 Pierde fuerza o contundencia ese principio general que los contratos no afectan a terceros, porque empezamos a clasificar a esos terceros, hablamos así de efectos directos o indirectos, en fin.... vemos en la casuística del código casos perfectamente establecidos, como la estipulación a favor de terceros, la donación con cargo a favor de un tercero, etc, que nos hacen ver que no es algo extraordinario que de una relación contractual, se genere algún efecto hacia otra sujeto que no interviene en la génesis de ese convenio.

Es difícil establecer que es un "tercero", generalmente lo definimos siempre en sentido negativo, diciendo que el tercero es aquel que no es parte, y entonces viene la necesidad de establecer quien es parte, y en esto me gusta seguir a López de Zavalía que diferencia entre parte formal y parte sustancial, "Parte formal es quien emite la declaración de voluntad. Parte sustancial es el titular de la esfera de intereses que el contrato tiende a regular." Sería muy simple si la distinción fuera simplemente formal, pues este sujeto no está presente al emitirse la declaración de voluntad común, pero el tema va más allá y tenemos que ver también si afecta su esfera de interés. Por lo tanto vale aclarar que debemos entender por partes no solo aquellos que han intervenido en el negocio, sino también aquellos que demuestren al escribano un interés legítimo, como sería para Gonzalez el heredero instituido en un testamento a la muerte del causante..$^{2}$

Los testimonios tienen una numeración ordinal, por eso el antiguo 1007 decía "Siempre que se pidiesen otras copias por haber perdido la primera". El nuevo Código Civil y Comercial no dispone esta exigencia, solo se refiere al tema cuando establece una excepción a la obligación del escribano de dar copias o testimonio, y allí habla de cuando la parte "solicita nueva copia", o sea no hace mención a la numeración de las copias. De todas maneras dejó claro que la misma se obtiene "conforme a las reglamentaciones locales" y la ley provincial nos reglamenta colocar "si es el primero, segundo o sucesivo expedido" (art 62 ley 4183) o también cuando establece que en la misma nota marginal debemos colocar esta información (art 63 ley 4183). El nombre de ese nuevo testimonio será segundo, tercero, cuarto y así sucesivamente, es una cuestión de lógica, de esta manera sabremos cuantos testimonios ya le hemos expedido a esa parte, con solo leer la nota marginal en la matríz. De todas maneras en cuanto a los efectos, la única diferencia importante es para la primera, pues las otras segunda, tercera, etc corren la misma

\footnotetext{
9 D'ALESSIO, Carlos Marcelo en "Código Civil y Comercial Comentado" Director Ricardo Luis LORENZETTI, Ed Rubinsal Cuzoni, Santa Fe, Tomo II p. 207.

10 ORELLE, Jose María Rodolfo. Algo más de la compra de inmuebles para terceros, Derecho Notarial Nº1, Director Gabriel Ventura, Ed Zavalía, Bs As 2012, Pág. 8 .

11 LÓPEZ DE ZAVALÍA, Fernando J., Teoría de los contratos. Tomo I Parte General, Bs. As., Za רvalía, 1985, Pág. 290.

12 GONZALEZ, Carlos Emerito, "Derecho Notarial”, Ed La Ley, Bs As 1971, Pág 497.
} 
suerte (son todas nuevas copias).

No se puede otorgar a alguien un segundo testimonio (o nueva copia) sino le he expedido un primer testimonio (o una copia) por lo tanto, se entiende que la numeración es subjetiva y no objetiva. No voy a contar cuantas copias di de la matriz, sino cuantas copias le di de la matríz a determinado sujeto, o sea se debe tener en cuenta la persona para la cual se expide y entonces con respecto a ella veremos si es el primer Testimonio o el segundo, no con respecto a la escritura en si, y por lo tanto podemos sacar de esta varias primeras copias. Otros prefieren hablar de primer testimonio primer ejemplar, primer testimonio segundo ejemplar, etc, esto no hace diferencia, y es innecesario pues la nota marginal y el concuerda dicen para quien se expidió la copia y contando las notas marginales voy a saber cuantas primeras copias di de esa matriz, el número de ejemplar podría hacer pensar erróneamente que un ejemplar primero es mejor que un ejemplar segundo y no hay diferencia alguna.

Con relación a los testimonios digitales, la situación tiene que ser la misma, pues deberá haber la posibilidad de extraviar este primer testimonio y solicitar uno nuevo, que también respetando la ley deberá denominarse "segundo", "tercero", etc según corresponda.. Lógicamente esta situación va a ser mucho más difícil que se de en la práctica, puesto que el documento digital, tiene la característica por el sustrato material en que está realizado de que al ser copiado, la copia es totalmente idéntica al original, y pasamos a tener dos ejemplares iguales de este primer testimonio, pueden existir varios ejemplares de un mismo testimonio, todos ellos originales gemelos. ${ }^{13} \mathrm{Si}$ el requirente tiene la precaución de tener un respaldo de sus archivos digitales, va a ser mucho más difícil perder este testimonio.

\section{Las hojas de papel sellado}

Algunos historiadores indican a Holanda como la primera nación que implantó el papel timbrado allá por el año 1624, pero las exhaustivas investigaciones realizadas por D. Ángel Allende ${ }^{14}$ conducen a asegurar que España fue la primera nación del mundo que lo utilizó a partir del $1^{\circ}$ de enero de 1637, por Real Cédula de Felipe IV, de fecha 15 de diciembre de 1636.

Más adelante hubo también que reglamentar su uso, para evitar perjuicios al fisco y también por razones extrafiscales, puesto que como en principio quedaba al arbitrio de cada individuo los márgenes y la cantidad de líneas, llegó a usarse pocos márgenes, con casi ninguna separación de palabra a palabra, haciendo un texto casi incomprensible, por eso "se ordenó que los escribanos de Consejo extendiesen sus escrituras poniendo 35 renglones en cada plana y 15 palabras en cada renglón" luego se hizo extensiva esa

\footnotetext{
13 Esto es muy importante para entender al documento digital y considero que quienes mejor lo explican son Falbo y Di Castelnovo, observese lo claro de estos párrafos de su libro; "Lo primero que debemos destacar aquí es que la materia, en los documentos digitales, resulta ser de menor relevancia que en el resto de los documentos. Observemos que un documento digital puede copiarse íntegramente y así aquella extensa cadena de bits agrupados se replicará de manera idéntica a la cadena original. A su vez este proceso puede repetirse indefinidamente, generando copias idénticas del mismo documento. Al respecto sostiene Rodríguez Adrados que "( ... ) los documentos electrónicos presentan una materialidad de menor incidencia el documento, porque un soporte electrónico puede ser sustituido por otro con permanencia del mismo documento ( ... ) el documento electrónico puede pasar de un cuerpo a otro, de un soporte a otro, manteniendo su identidad; un soporte le es siempre necesario, pero los soportes concretos son intercambiables, totalmente accidentales" En efecto en términos informáticos resulta apropiado hablar de "clonación" de los documentos, más que de "copias". No creemos. que esta particularidad presente problema alguno con la concepción material del documento digital, solo la ponemos de resalto para comprender sus peculiares características. Podemos concluir, pues, en que el soporte material del documento digital está dado por los metales con propiedades magnéticas en los que se alojan los bits que lo componen" FALBO Santiago y DI CASTELNOVO, Falbo "Nuevas Tecnologías Aplicadas a la Función Notarial", Di Lalla Ediciones, Buenos Aires 2019.

14 ALLENDE Ángel, Timbres españoles. Barcelona, 1969.
} 
obligación a los escribanos del Reino”'15.

Lógicamente que en un primer momento, el papel sellado que se utilizó en el país fue el mismo que en España, pero comienza la historia de nuestro papel sellado a partir de la resolución de la Asamblea del año 1813. Vamos a tener papel sellado nacional hasta 1820, cuando comienza la etapa donde el papel sellado provincial pasa a ser provincial' ${ }^{16}$

Tenemos que tener presente que el papel sellado es una forma de pago de un impuesto, o sea la modalidad de un tributo exigido por el estado para contribuir al sostenimiento del Estado, a quienes instrumentaran actos o contratos (este es el hecho imponible). El impuesto nació con esta modalidad, ya que hacía fácil la recaudación, y fue la única en un principio, entonces el impuesto tomó el nombre de dicha modalidad.

No cabe dudas que las cosas fueron cambiando, si bien este impuesto empezó a cobrarse con la modalidad de la venta del papel sellado o papel timbrado, con el correr del tiempo fue reemplazado por otro elemento más moderno, como la estampilla, entonces se permitió que los contratos o actos se redactaran en papel común y se pagara este impuesto con la compra de estampillas ${ }^{17}$, que también se llamaron sellos o timbres. Lógicamente que no fue reemplazado solamente por ser un sistema más moderno, sino porque el valor a pagar ya no era siempre el mismo, de acuerdo a las cantidades de hojas de papel utilizadas, sino que se empezó a hacer diferencias según el monto establecido en el contrato o acto instrumentado. Si bien existieron distintas tipos de hojas de papel sellado (judiciales, administrativas, notariales) y con distinto valor, ellas no eran suficientes para dar lugar a la complejidad alcanzada por el impuesto y la modalidad tuvo que ser cambiada.

Lo más importante de este papel sellado es que además de ser una manera de recaudar para el estado, consiguió cumplir con otro objetivo, el de brindar mayor seguridad, por lo difícil que se hace falsificarlo o adulterarlo (pensemos en la simple exigencia de determinada cantidad de renglones), por eso entonces las Escrituras pese a pagar el impuesto al estado por medio de estampillas, o boletas de depósito, coexistió con el papel sellado y hoy en día se sigue utilizando más que nada por este otro fin.

¿Cuándo se empezó a dejar de utilizar significativamente el papel sellado como modo de recaudar este impuesto a la instrumentación de contratos? Pues, en el caso de las escrituras, recién en la última mitad del siglo XX. En Córdoba se desdobló el pago del impuesto de sello por un lado mediante el pago de hojas de papel sellado y por otro lado mediante un formulario especial donde se establecía una alícuota del monto establecido en el contrato o un monto fijo, dependiendo del acto o contrato instrumentado. Luego la impresión de esas hojas de papel sellado, fue delegada por el estado provincial en una persona jurídica de carácter público, el Colegio de Escribanos, más precisamente el 19 de mayo de 1969 mediante el decreto 3416 que incorporaba como Art 58 (bis) de la reglamentación de ley orgánica del notariado (en ese entonces Dec 2214 Serie A/67) ... "La impresión del papel timbrado para cuadernos de protocolos y de actuación notarial será realizada por el Colegio de Escribanos de conformidad a la ley 4183 y al Código

15 PELOSI, Carlos A."Las notas en el Protocolo”, Revista del Notariado Nº22 de 1955.

16 PICCON, Augusto "Papel sellado", Revista Notarial Nº3-84 de 2004

17 Esta forma de pago mediante estampillas también ha sido utilizado por otros impuestos, por ej los impuestos aduaneros, que gravan al importación de productos, o impustos internos como los del tabaco etc. 
Tributario de la Provincia..." ${ }^{18 "}$ Hoy en día se encuentra esta directiva en el Art 43 de la ley que dice ... "Las escrituras públicas se extenderán en cuadernos de papel de diez folios cada uno, con sello y timbre especial para protocolo, cuyas medidas, membrete, formato y demás características serán establecidas por el Colegio de Escribanos. La impresión de los respectivos cuadernos será efectuada por el Colegio, con numeración correlativa y ordenación por Serie"

O sea que si bien desapareció el impuesto de sellos en el papel sellado que le dio origen, nos quedó el papel sellado a los fines de brindar seguridad a la documentación notarial. Las hojas de papel señado en las que se realizan los testimonios actualmente son llamadas las hojas de "Actuación Notarial" y cuentan con un número de serie con el cual se le hace un seguimiento, se puede saber que escribano la adquirió en qué fecha, cuando expidió el testimonio, etc; tiene un holograma de seguridad, tinta invisible ultravioleta, filigranas, micro letras y otras medidas de seguridad para evitar falsificaciones y adulteraciones. Se ha logrado con esto contar con papelería de seguridad como ninguna otra institución pública o privada a logrado contar.

¿Qué pasa con estos testimonios que podría hacer el notario en formato digital?, ya no utilizarían evidentemente las hojas de papel sellado, por el sustrato físico o material en el cual van a desplazarse, pero sin duda alguna podemos decir que sería bueno que estos testimonios también contaran con un control y seguimiento por parte del Colegio de Escribanos, por cuestiones de seguridad. Asi como se podría verificar si un testimonio está impreso en hojas compradas por un escribano en ejercicio y que comunicó haber realizado ese testimonio, así también se podría saber la misma información de un testimonio en soporte digital. Esta búsqueda de reducir diferencias y aumentar exigencias que brinden seguridad, además de lograr no tener testimonios de primera y de segunda, no disminuyen las ventajas de las características que hacen a cada soporte. Como bien dicen Falbo y Di Castelnovo "se debe prever la existencia de folios digitales, esto es, un elemento oficial y estandarizado en el que se plasme la actuación notarial digital."19

\section{Notas Marginales en relación a los testimonios}

La Nota Marginal desde el punto de vista formal, es un instrumento público. Es un instrumento público notarial, pues el funcionario que lo realiza es el escribano. Desde el punto de vista sustancial es una certificación $\left({ }^{20}\right)$ que hace el escribano de haberse producido un hecho, o de la existencia de algún documento que, en ambos casos, tienen relación con la escritura, y al igual que los certificados se diferencia con las actas en que en estas últimas hay declaraciones de las partes o sujetos instrumentales, en tanto que aquí como en el certificado, por ser documento de ciclo cerrado, hay únicamente declaraciones del escribano. La diferencia con el certificado es que en este caso no hay rogación

\footnotetext{
18 "Decreto 3516 Notariado - Sellado a cobrar - Modificación de la reglamentación de la ley notarial. Fecha 19 mayo 1969 Visto la presentación del Colegio de Escribanos de la Provincia de Córdoba, sugiriendo la modificación del dec. Reg. De la ley notarial 4183, a fin de incorporar una norma que soluciones el problema planteado por no haberse previsto en la ley impositiva 1969, el sellado a cobrar por los cuadernos de protocolo y para la expedición de los testimonios de escrituras: Atento lo informado por el Ministerio de Economía y Hacienda, la opinión emitida por el Tribunal de Disciplina Notarial, Asesoría General del Ministerio de Gobierno y Fiscalía de Estado (dictamente 451/1969). El Gobernador de la Provincia, decreta: Art $1^{\circ}$ Amplíase la reglamentación de la ley notarial 4183 (IX-B-2092) Dec 2214-Serie "A"/67, incorporándose a la misma el siguiente: Art 58 (bis) Las escrituras públicas y sus testimonios serán confeccionadas por los escribanos, con sello y timbre especial, cuyas medidas, membrete, formato, etcétera, serán establecidos por el Colegio de Escribanos de la Provincia. La impresión del papel timbrado par cuadernos de protocolo y de actuación notarial será realizada por el Colegio de Escribanos, de conformidad a la ley 4183 y al Código Tributario de la Provincia, en lo que respecta al tamaño, número de líneas, numeración correlativa y ordenación por series. Art $2^{\circ}$ Comuniquese, etc - Caballero - Martínez Golleti” ADLA XXIX-B, Córdoba, Pág 2149..

19 FALBO Santiago y DI CASTELNOVO, Falbo “Nuevas Tecnologías Aplicadas a la Función Notarial”, Di Lalla Ediciones, Buenos Aires 2019.

20 "La palabra certificado deriva del verbo "certificare", que significa "hacer cierto" (de "certas", cierto, y "facere", hacer)... Sin olvidar que hemos sostenido que las notas marginales de subsanación son más certificados que notas." PELOSI Carlos A., "Los Certificados Notariales", Revista del Notariado 716 de 1971.
} 
de las partes, si... no hay rogación de las partes, pero hay un deber funcional que la ley nos impone, de dejar constancia.

El error que comenten los distintos autores en general es confundir el verdadero fin de la Nota Marginal, que es su ¿por qué? o sea el fin último, con el objeto concreto que persigue cada nota marginal, o sea el ¿para qué? o el fin inmediato, que es solo un aspecto de ella.

Considero que el fin que tiene la nota marginal, es justamente dar a conocer, dar publicidad, dejar una constancia para que alguien se entere, ya sea el propio escribano, ya sea alguien más que está haciendo un estudio de títulos, o porque no el que más adelante deba expedir un testimonio. $Y$ este fin que tiene toda nota marginal, es parte de su esencia, tan es así que por eso que se la hace en el mismo lugar material del instrumento al cual complementa, al cual está subordinada, o mejor dicho con el cual tiene una estrecha relación.

En nuestra ley 4183 se exige hacer nota marginal al expedir un testimonio colocando para quien se expide si es primer o ulterior testimonio y la fecha de expedición; y cuando se encuentre sujeto a inscripción también deberá dejarse constancia de la misma (art 63). También se exige hacer otra nota marginal pero esta vez en el testimonio de la escritura antecedente no en la matriz, dejando constancia del acto otorgado (Art 66).

Por lo tanto las notas que tienen que ver con la expedición e inscripción de este testimonio digital, a realizarse ambas notas en el protocolo no tienen modificación alguna, el problema está con la nota que se debe realizar en el título antecedente, cuando el mismo haya sido presentado en soporte digital, puesto que aunque podamos hacer un nuevo documento (nota marginal) que se integre al anterior, puede haber otros archivos que no la contengan. Recordemos que se pueden hacer muchos clones de este archivo. Por lo tanto no voy a estar seguro cuando me presenten un testimonio digital si puede existir un clon dando vueltas por allí con nota marginal y me entregaron uno sin la misma. De todas maneras como dijimos la nota es al solo efecto de realizar publicidad, la llamada publicidad cartural, muy importante sobre todo en la época de Velez cuando no existía la publicidad Registral y de menor importancia al advenimiento de ella, pero que es importante porque la seguridad, como se dice no depende de un solo procedimiento sino de varios que actúan conjuntamente. Hoy en día también se puede evitar mostrar una nota marginal, cuando se simula el extravío del primer testimonio y se solicita un segundo testimonio del mismo, y aunque esto nos puede estar indicando algo, no es del todo segura por si sola esa publicidad cartural. Por esa razón una de las posibilidades que tenemos es inventar un nuevo método paralelo de brindar esta información, y si tenemos un sistema de control y seguimientos de los testimonios digitales, poder brindar noticias en relación a ellos en este sistema. Eso si no será específicamente publicidad cartural, pues no acompaña al archivo, sino que surge de su verificación en una base de datos fuera de él. Lo cierto es que si se permite este soporte para hacer el testimonio y de no estar previsto un método alternativo como el señalado, el escribano no va a caer en responsabilidad alguna, al no realizarla, ya que la norma se tornará de cumplimiento imposible.

\section{Testimonio como instrumento público}

Una cosa a tener en cuenta con el testimonio, es que este es un instrumento público tal cual lo establece el Código Civil y Comercial de la Nación en el Art 289 "Enunciación. 
Son instrumentos públicos: a. las escrituras públicas y sus copias o testimonios". Este instrumento público no deja de ser tal por cambiar de soporte, la característica de ser un instrumento público no deviene del soporte utilizado sino del autor que lo realiza ${ }^{21}$.

Por lo tanto este testimonio digital es un instrumento de mayor jerarquía del resto de los documentos digitales, porque el autor del mismo es un Funcionario público fedatario, en ejercicio pleno de lo que es su competencia material, o sea está labrando el instrumento que le corresponde hacer según la ley. Esto implica un salto no solo cuantitativo en cuanto al valor probatorio del mismo en relación a otros documentos digitales, sino también cualitativo por todas las ventajas que se desprenden del autor del documento y los ritos y exigencias legales con las que este realiza su labor. Siempre hay que tener presente que la firma digital no hace al documento auténtico, la ley equipara la firma digital a la ológrafa, para que haya documento auténtico es necesario de la intervención de un funcionario fedatario, pero de este tema ya muchos autores han expuesto y excede el punto que queremos tocar.

\section{Segundos y sucesivos testimonios de escrituras donde surgen obligaciones pendientes} El principio es que el escribano debe dar copia o testimonio a la parte que lo requiera, y no solo una, sino todas la que requiera (segundo, tercer, cuarto testimonio, etc), pero esta regla tiene una excepción, y por lo tanto hay que analizarla como tal. El notario, no podrá extender un segundo testimonio, o como dice el nuevo código una "nueva copia" si existen obligaciones pendientes, así lo exigía el Código de Velez en su Art 1007 puesto que "si en la escritura, alguna de las partes se hubiese obligado a dar o hacer alguna cosa, la segunda copia no podrá darse sin autorización expresa del juez". Y el nuevo código lo vuelve a establecer, pero lo hace de manera diferente así dice "Si alguna de las partes solicita nueva copia, el escribano debe entregarla, excepto que la escritura contenga la constancia de alguna obligación pendiente, a cargo de otra de las partes", subrayando la última parte de la normativa, porque va luego a ser importante para su interpretación.

Como bien dice Ventura, el nuevo Código "superando en practicidad al código derogado" 22 , exige como lo dice el art 308 "la acreditación en instrumento público de la extinción de la obligación, la conformidad del acreedor o la autorización judicial, que debe tramitar con citación de las partes del acto jurídico".

Esto es tomar parte de lo que la doctrina venía proponiendo, había supuestos en los que perdía sentido, por ejemplo, si se podía acreditar de algún modo fehaciente, el cumplimiento de la obligación, y así lo reguló el 308 pues posibilita la acreditación del estar cumplida ya la obligación pendiente con un instrumento público (por lo tanto con pleno valor probatorio), con lo cual cae el supuesto fáctico, que establecía la excepción para no dar copia.

\footnotetext{
21 "Un certificado no es técnicamente un contrato ni un acuerdo de ninguna naturaleza, sino una corroboración unilateral de una situación determinada; por ello sostenemos, aun en el marco de la ley 25506, conforme a su art. 3, que los dichos certificados pueden ser suscriptos por una sola de las partes, mediante la llamada firma digital, sin mengua de su valor documental, sea de instrumento público, sea privado según estén autorizados o no por el funcionario público competente en uso de su atribución fedataria". VENTURA, Gabriel B, "Certificado Registral expedido con Firma Digital" Revista del Notariado $\mathrm{N}^{\circ} 95$, año 2017.

22 VENTURA, Gabriel B, “Testimonios y Copias en el Nuevo Código Civil y Comercial de la Nación”, en la página web de la Academia Nacional de Derechos y Ciencias Sociales de Córdoba, http://www.acaderc.org.ar.
} 
También la doctrina opinaba en ese entonces, con el antiguo código, como lo hacía Gattari, que no era necesaria la autorización judicial si todas la partes se ponen de acuerdo en que se expida un segundo testimonio para una de la partes, y sostenía que ese era criterio de los archivos de protocolos de Bs As y La Plata. ${ }^{23}$ Lo cual caía de maduro, pues qué sentido tenía llegar a una instancia judicial sin conflicto posible alguno.

Sin embargo, el nuevo código Civil y Comercial parecería establecer en principio una norma más amplia en este sentido, porque posibilita la expedición con la conformidad del acreedor (sería el caso de que lo pida el deudor) pero no menciona la conformidad del deudor, o sea se podría entender en principio que cuando lo pide el acreedor, no sería necesaria la conformidad de la otra parte. El problema está en designar al acreedor solamente como el sujeto que deba prestar conformidad, en esto entendemos, hay un error. Como ya lo analizamos antes con profundidad en otro artículo ${ }^{24}$ el fundamento que tiene esta norma, que viene de muy antiguo, es la protección del deudor. La norma tiene dos pasajes contradictorios. Por una lado, lo que salta más a la vista, nos habla de "la conformidad del acreedor" para no recurrir a otro remedio como la autorización judicial, que nos permitiría dar copia. Pero por otro lado la norma, establece en otro pasaje la imposibilidad para el notario de dar nueva copia, aquí hace referencia a que la obligación sea "a cargo de otras de las partes", o sea el supuesto principal no está completo con solo decir "cuando haya obligaciones pendientes" (como lo decía en cierta manera el 1007), sino que el supuesto es más complejo, seria en realidad "cuando haya obligaciones pendientes para la otra parte que no pide el testimonio", o sea la norma parecería impedir al escribano expedir al acreedor la copia, no al deudor, porque necesariamente quien tiene a cargo una obligación no es el acreedor sino el deudor. Por lo tanto si leyéramos la norma de esa manera, o sea como que no se puede expedir nueva copia al acreedor si la obligación estuviera pendiente, y este es el supuesto que toma en cuenta la norma para la segunda parte, carecería de sentido su conformidad, es más, él la va a pedir, no agregaría nada. Esto quizás se debe a que el agregado ese, "conformidad del acreedor" fue realizado de último momento, no estaba en el anteproyecto ni en el proyecto, fue agregado al sancionarla.

Como decíamos el fundamento ${ }^{25}$ que tiene esta norma, es la protección del deudor, ya

23 GATTARI Carlos Nicolas, “MANUAL DE DERECHO NOTARIAL”, Editorial Depalma, Buenos Aires 1988, pág 188.

24 PICCON, Augusto "Testimonios con obligaciones pendientes", Revista de Estudios de Derecho Notarial y Registral, Universidad Blas Pascal Año 5 $\mathrm{N}^{\circ} 5$ (2018).

25 "Esta norma viene de muy antiguo, cuando se empezó a forjar el instrumento público en el ámbito privado "Carminio Castagno, rastreando las fuentes tenidas en cuenta por Vélez Sarsfield para la redacción de los arts. 1007 y 1008, a través de sus notas, llegó a la conclusión de que el codificador se basó en la legislación de las Partidas. Realizando una interpretación histórica de los artículos mencionados, señalaba que la razón para exigir la autorización judicial previa a la expedición de la nueva copia se da solo en los supuestos en que pueda seguirse, para el deudor un "grave daño": el nuevo cumplimiento de la obligación emergente del acto jurídico instrumentado. Por ello es que, el derogado art. 1008 exigía la previa citación de los sujetos pasivos de la obligación, a los fines de que pudieran oponerse — ofreciendo y rindiendo prueba - a la expedición de la segunda o ulterior copia. ... nos parece acertada la norma del nuevo Código en cuanto permitiría que, mediante acuerdo entre deudor y acreedor, se pida una segunda o ulterior copia de la escritura directamente al notario sin dar intervención judicial, pues el interés protegido por la norma es únicamente el del sujeto obligado. También para analizar el fundamento, la jurisprudencia nos ayuda con casos que la doctrina ha analizado, y asi "Salvat hace una distinción según la índole de las obligaciones de dar o hacer que la escritura contenga. Las que su cumplimiento o ejecución no pueda ser nuevamente requerida el escribano puede expedirlas sin necesidad de autorización judicial... No habiendo quedado entonces nada pendiente, ningún perjuicio podría ocasionar que una de las partes tuviese dos o más copias en su poder, porque la relación jurídica que tuvo lugar entre los otorgantes, ha quedado finiquitada... García Goyena en el art 1216 es más terminante. Siendo la escritura de aquellas por las que el acreedor no tiene acción para pedir sino una vez la cosa, como son las de venta, permuta, donación, etc, puede el escribano darlas sin necesidad de que el juez lo mande, ni oir a los interesados..."

Uno está acostumbrado a ver al acreedor retener el testimonio del deudor para "impedir que éstos puedan disponer de su bien al no ostentar la titularidad cartular correspondiente (art. 23 de la ley 17.801)” pero este no es el fundamento de la norma, y hasta discutible ese derecho de retención, cuando no se puede obligar una persona en un contrato oneroso a no vender a persona indeterminada (art 1972), la no existencia en nuestro régimen legal de la inhibición voluntaria, e ir en contra de lo que el legislador busca con la especialidad en cuanto al monto de la hipoteca, si hubiere estado garantizado el crédito con ella. Sin embargo, suponiendo que le damos cabida, como un pacto que debería respetarse, para asegurarse conocer sobre una condición a la que esté subordinada el plazo de la obligación, o porque quiere conocer quien ocupa el inmueble (en caso de que el deudor sea propietario), o porque le interesa al acreedor que mientras esté pendiente su derecho, se conozcan ciertas constancias cartulares, pues como dice Ventura "mediante la expedición de un nuevo 
que el acreedor con este instrumento, el testimonio, puede accionar, tiene un título ejecutivo y esto en combinación con la arraigada costumbre que existe en relación con los instrumentos privados, que consistente en entregar o destruir el documento cuando paga el deudor, para demostrar que no va a accionar (La típica frase "lo rompemos y listo"). El común de la gente no se percata que estamos en el ámbito del instrumento público, donde lo que circula es una copia de la matriz. Por lo tanto, si le entregamos un segundo testimonio al acreedor, le podemos hacer un mal al deudor que va a entrar en un juicio (a veces ejecutivo) donde tenga que demostrar que no debe, con muy pocas excepciones para defenderse, y sin haberse precavido de pedir el otorgamiento de un recibo.

Con el testimonio digital, en principio mientras la norma subsista se deberá aplicar igual procedimiento. Dejando de lado que debería analizarse si la norma tiene el mismo beneficio que otorgaba antaño, cuando recién comenzaba el uso del protocolo Una cosa es seguro, cuanto más testimonios digitales haya, mayor va a ser la inutilidad de la norma. Más allá de que muchos deudores, cuando la obligación es importante buscan documentar el recibo de cobro y no se contenta solo con la destrucción de la cartula donde consta la obligación, con el uso cada vez mayor del sustrato digital nadie va a pensar que eliminando el archivo del disco duro, del pen drive, etc va a eliminarse el documento, cuando puede haber sido resguardado en otro dispositivo con exactamente las mismas características.

Además hay que reconocer que sería muy probable que el escribano guardara una copia de ese documento digital en algún soporte, o sea una copia del documento digital entregado en este caso (primer testimonio digital) y podría volver a pasárselo a su requirente, sin necesidad de generar un segundo testimonio, porque como analizáramos anteriormente la copia es un documento clonado o sea no se podría diferenciar entre copia y original. Ambos serían originales por igual.

Entiendo que la numeración del testimonio no debería hacer diferencia entre el testimonio en papel y el testimonio en sustrato digital. Podría entregarse un primer testimonio en papel, luego el segundo testimonio en forma digital y el tercero en papel, según como lo pida la parte, y le sea más provechoso.

También se podría pensar en la situación que necesitemos que el primer testimonio se otorgado digitalmente para su inscripción, pero luego la parte quiera contar con algo más que ese testimonio digital, quisiera tener algo en soporte papel. Entiendo que también que el Notario podría hacer una copia certificada en soporte papel del documento digital, que por supuesto (como nos explayáramos en el primer tema del desarrollo) será solo simple copia (aunque esté certificada) pero no testimonio y por supuesto dejando constancia siempre de haber tenido a la vista y verificado en el ordenador la firma digital del mismo.

\section{Caso de pluralidad de partes}

Partiendo de lo que dijimos antes, en caso de pluralidad de partes cada una de ellas, cada sujeto que ve afectado su esfera de intereses, tiene derecho a su copia, a su testimonio, más allá de que del testimonio digital puedo obtener clones, debo realizar un

testimonio, se hace desaparecer virtualmente cualquier nota marginal de correlación o aclaratoria que hubiere sido insertada en el primer testimonio" Aún así es bastante rebuscado ver la posibilidad del daño en esta expedición de copia." PICCON, Augusto "Testimonios con obligaciones pendientes", Revista de Estudios de Derecho Notarial y Registral, Universidad Blas Pascal Año $5 \mathrm{~N}^{\circ} 5$ (2018)... 
testimonio para cada uno, en sellos diferentes, con la nota marginal correspondiente, para que este pueda ejercer su derecho, para poder mostrar o demostrar el negocio jurídico realizado.

Aquí debemos aclarar que todo sujeto que ve afectada con el contrato su esfera de interés es parte, pero hay partes que tienen derechos convergentes en un mismo sentido, y de esta forma podemos hablar que integran una parte del contrato, el ejemplo clásico son los compradores en condominio, ellos integran la parte compradora del contrato, o sea son los que tienen un derecho en contraposición a la parte vendedora de la cual surge una obligación en relación a ese derecho. Pero aun así cada uno de esos compradores es parte y aunque en el mismo sentido que el otro comprador, su derecho es independiente. Por supuesto que cada caso concreto tiene su complicación para analizar esta situación en la que encuentran los protagonistas de un negocio.

\section{Integración al SIDANO}

(SISTEMA VERIFICADOR, INTEGRADOR Y ADMINISTRADOR DE DATOS NOTARIALES)

Cabe recordar brevemente, que hasta el año 2000 (con la existencia del fondo común), el depósito de honorarios, tasas, sellos y aportes se hacía mediante una boleta única. El colegio controlaba el monto de cada ítem de esa boleta, visaba la escritura y llevaba un control de las escrituras realizadas por cada escribano, y por ende por todos los escribanos de la provincia, contando con datos estadísticos muy importantes y por otro lado controlaba también que los escribanos tuvieran al día el pago de todos los ítems correspondientes a cada escritura.

Con la desregulación de honorarios, el colegio dejó de manejar el pago del fondo común y por consecuencia ya no se hacía el depósito de los honorarios en la cuenta del Colegio, como así también dejó de hacerse una boleta única por escritura con todos estos montos (aportes, sellos y tasas) cada repartición implementó su boleta de pago.

Luego de varios años y con problemas serios de por medio, como la megacausa, las instituciones del estado relacionadas con el tráfico inmobiliario y el Colegio de Escribanos, resolvieron implementar un sistema de visado de las escrituras, para que hubiera un cierto control de las mismas y un control del pago de sellos y tasas. Fue el mencionado POSDIN (Plan de Optimización del Sistema Dominial Inmobiliario de la Provincia de Córdoba).

La visación estaba a cargo del Colegio de Escribanos, con la ardua tarea de cargar todos los datos de las escrituras que eran visadas antes de entrar al Registro. Herramienta que le permitia verificar el uso de sellados de actuación propios de ese escribano, que el mismo estaba en ejercicio, etc y de esta manera ayudar en forma preventiva a verificar la autenticidad de los testimonios de escrituras labradas por Escribanos de la Provincia de Córdoba; y efectivizar la vigilancia del uso de las hojas de protocolo.

Y así llegamos al SIDANO. Este sistema entró en vigencia a partir del 1 de julio de 2016 (coexistiendo por 90 días con el procedimiento anterior, POSDIN) ${ }^{26}$,. Es parte de un pro-

26 Visto el Convenio suscripto entre el Gobierno de la Provincia de Córdoba (a través de la Dirección General de Rentas, la Dirección General de Catastro y el Registro General de la Provincia) y el Colegio de Escribanos de la Provincia de Córdoba, con fecha del 25 de junio de 2008 referido al Plan de Optimización del Sistema Dominial Inmobiliario de la Provincia de Córdoba (POSDIN), la Institución Notarial resolvió el sesión del Honorable Consejo Directivo del 9 de mayo de 2016, que a partir del $1^{\circ}$ de julio del mismo año, se implementara el SISTEMA VERIFICADOR, INTEGRADOR Y ADMINISTRADOR DE DATOS NOTARIALES (SI.DA.NO) del Colegio de Escribanos de la Provincia de Córdoba. 
yecto general de servicios para el escribano por Internet y una herramienta informática que simplifica la tarea administrativa. Uno de los ejes centrales es permitir la integración con otras reparticiones públicas para evitar la reiteración de la carga de un mismo dato en los sistemas informáticos, como actualmente se ha logrado hacer con la Caja Notarial y con la Dirección de Rentas en cuanto al pago del impuesto de sellos. O sea esos datos de la escritura, cargados en el sistema del Colegio, son utilizados por la Caja Notarial para la declaración mensual a los efectos del pago de aportes, y son utilizados por la Dirección de Rentas para el pago del impuesto de sellos de esa escritura.

La implementación del SIDANO se tomó considerando este objetivo trazado en mencionado Convenio del POSDIN. La carga de datos actualmente ya no significa una pesada carga, desde que la misma carga ya sirve actualmente para no cargar más los datos en un sistema diferente como el de los aportes, o como el de rentas para el pago del impuesto de sellos. Además ahí también un objetivo de control, recordemos que dentro de las funciones asignadas al Colegio (Ley 4183), se encuentran las de velar por el cumplimiento de las normas y del reglamento notarial, y que es necesario adecuar los sistemas de control a los medios técnicos con que cuenta la sociedad.

El Sistema Verificador, Integrador y Administrador de Datos Notariales, sistema de información diseñado por el Colegio de Escribanos de la Provincia de Córdoba, es perfectamente el sistema donde hay que anexar esta plataforma para el otorgamiento de sellos digitales. Más allá de la autorización del Tribunal de Disciplina para realizar los testimonios con otro soporte, esa autorización debe estar dada en un marco regulatorio, o sea hay que preveer y establecer claramente ese mecanismo, como ya lo han realizado otros colegios del país (CABA, Buenos Aires) ${ }^{27}$, El colegio deberá asignarle los folios digitales de Actuación Notarial al momento en que el Notario coloque su firma digital en el Documento, integrando el folio digital a los datos de ese documento digital. El Colegio deberá, mediante este sistema validar previamente que quien solicite adquirir dichos folios sea un escribano en ejercicio, y pedir la carga de datos de la escritura matriz (Número de escritura, fecha, foliatura del protocolo, sellos del protocolo, etc), de igual manera como se hace con los testimonios en formato papel.

En ciudad de Buenos Aires ya existe el dentro del Acceso Restringido Web del CECBA el "Sistema para la Generación de Documentos Notariales Digitales" (GEDONO) de uso exclusivo para los escribanos de esa demarcación con el objeto de permitir la expedición en soporte digital de los documentos extraprotocolares, cuya reglamentación del corriente año en su art 2 incluye inc d) ACTUACION NOTARIAL ART.308 CCCN. Inc e) CONCUERDA DIGITAL.

En la provincia de Buenos Aires tienen implementado el SIESBA de uso obligatorio a partir de septiembre de 2016, y en reemplazo del SiPrEsBA, la Agencia de Recaudación de la Provincia de Buenos Aires implementó un sistema web (SiEsBA), para efectuar la presentación de declaraciones juradas y pagos. Se trata de un sistema global de gestión notarial que abarca la solicitud de certificados catastrales, la liquidación y pago del impuesto de sellos y de los aportes notariales, la liberación del impuesto inmobiliario, la confección de la minuta de inscripción en el Registro de la Propiedad, y la calculadora

27 Reglamento del Uso de la Firma digital, dictado por el Colegio de escribanos de la ciudad de Buenos Aires por resolución 50/14 según Acta 3889 de fecha 14 de febrero de 2014 que entre otras normas dice en su Art 5 prevee la validación por parte del Colegio de la matriculación del escribano y que esté en ejercicio al momento de la firma digital. En el art 6 prevee el cobro tanto por el documento digital que se otorgue y por el proceso de validación, etc. 
para liquidar la tasa de inscripción. Como el sistema no es propio del Colegio de Escribanos para los documentos digitales debió crear una plataforma diferente y así mediante resolución del CONSEJO DIRECTIVO DEL COLEGIO DE ESCRIBANOS DE LA PROVINCIA DE BUENOS AIRES se dicta el REGLAMENTO para las actuaciones notariales previstas en los arts. 166 a 177 de la ley 9020 en soportes digitales, y por ese motivo en su normativa expresamente establece que "son requisitos generales de las actuaciones notariales en soportes digitales, excepto que por este reglamento se establezcan otros: a) La utilización de la Plataforma de Gestión Documental Digital desarrollada por el Colegio de Escribanos de la Provincia de Buenos Aires"

Entiendo que el documento digital en si no debería quedar registrado, almacenado, en el Colegio (sus bases de datos), como tampoco queda almacenada una imagen del testimonio en papel. Pero si tiene que estar la posibilidad de verificar la carga de ese testimonio en el sistema y con esos folios de Actuación asignados (como venimos haciendo). El sistema al ser automático de por si, no genera siguiera inconvenientes en cuanto al secreto profesional, de todas maneras también tendríamos que tener en cuenta que el Colegio en si, cuenta con la regencia del Archivo de Protocolos, o sea aunque guardara una copia del testimonio no tendría, en su base de datos más información de la que ya cuenta en el Archivo.

En el caso de los documentos digitales es recomendado la posibilidad de generar un Código de Verificación. "Asimismo la propia informática ha generado otras herramientas de seguridad, entre las que podemos destacar al Código Seguro de Verificación (CSV), elemento que se utiliza para vincular un documento digital en concreto con un código específico, que puede considerarse de gran utilidad en la implementación de los documentos notariales digitales. De esta manera el documento digital cuenta con un código mediante el cual se puede acceder al mismo documento digital, o a algún dato de él, por lo general, ingresando en una página web específica. En la práctica el código está compuesto por una larga cantidad de letras y números que aparece visibles en el documento, previendo la situación de que el usuario lo imprima, lo que permite recuperar el documento digital desde su impresión al papel." ${ }^{28}$ De esta manera también se le da otra seguridad al receptor del documento notarial, el que pueda acceder por el sistema a este Código de Verificación.

Por todo esto creemos que con toda la experiencia que se viene sumando con el SIDANO, sería de muy fácil la implementación de un anexo para una plataforma de gestión de documentos digitales.

Todo está dado para la posibilidad de contar en Córdoba con los testimonios digitales, no debemos dejar pasar más tiempo, debemos brindar esta útil herramienta antes de que sea pedida a gritos. El poder de circulación del documento digital, no solo se condice perfectamente con las finalidades del Testimonio que nació para dar vueltas en la comunidad, dejando resguardada la matriz, sino que le posibilita acelerar este potencial enormemente.

\section{CONCLUSIONES}

- Es factible la realización de un testimonio digital, sin necesidad de modificar la legislación provincial vigente, solo es necesario al

28 FALBO Santiago y DI CASTELNOVO, Falbo “Nuevas Tecnologías Aplicadas a la Función Notarial”, Di Lalla Ediciones, Buenos Aires 2019. 
efecto la autorización por parte del tribunal de disciplina.

- La ley exige del testimonio digital "permanencia indeleble". No son dos requisitos sino que debemos entender este requisito como una exigencia de que mientras dure no pueda ser modificado

- Es necesario poner en un pie de igualdad estos testimonios con los realizados en soporte papel y crear los sellos digitales de Actuación Notarial

- Los sellos digitales, como el papel sellado son un elemento más en post de la seguridad documental.

- Es necesario contar con una plataforma digital organizada por Colegio de Escribanos para poder brindar el sello digital, que debería ser parte del SIDANO.

\section{REFERENCIAS BIBLIOGRAFICÁS}

- GIMENEZ ARNAU, Enrique, “INTRODUCCIÓN AL DERECHO NOTARIAL”, Editorial Revista del Derecho Privado, Madrid 1944.

- GONZALEZ, Carlos Emerito, "Derecho Notarial”, Ed La Ley, Bs As 1971.

- NUÑEZ LAGOS, Rafael, "Documento público y autenticidad de fondo", Revista del Notariado $N^{\circ} 727$, año 1973

- GARCIA CONI, Raúl R, "El porqué de la escritura pública", Revista del Notariado 777 de 1981

PONDÉ, Eduardo Bautista, "Origen e historia del Notariado", Editorial Depalma, Bs As 1967, Pag 34

- ZINNY, Mario Antonio, "El Acto Notarial (Dación de fe)" 2Edición, Ed Depalama, Bs As 2000, Pág 8

- PELOSI, Carlos A. "El documento Notarial”, 3reimpresión, Ed Astrea, Bs As 1997,

- COURTIAL, Gastón "Presente y futuro de la profesión notarial”, Revista Notarial №804 de 1986.

- PELOSI, Carlos A. "La responsabilidad disciplinaria del Escribano", Revista Notarial, №710, abril 1970.

- LARRAUD, Rufino. "Curso de Derecho Notarial". Ed. Depalma, s. As.. 1966.

- GATTARI, Carlos N. "Manual de Derecho Notarial”. Ed. Depalma. 1988, Bs. As

- SIERZ, Susana Violeta, "Derecho Notarial - Concordado", 2Edición Actualizada y ampliada, Ed Dilala Ediciones, Bs As 2007

- ABELLA, Adriana, "Derecho Notarial- Derecho Documental - Responsabilidad Notarial" Ed Zavalía, Bs As 2005.

- ARMELLA, Crisitina (directora) y otros, "Tratado de Derecho Notarial, Registral e inmobiliario", 3 Tomos, Ed Ad-Hoc, Bs AS 1998

- NERI Argentino, "Tratado teórico práctico de Derecho Notarial”, 6 tomos, Ed Depalma 1969

VENTURA, Gabriel B, "Testimonios y Copias en el Nuevo Código Civil y Comercial de la Nación", en la página web de la Academia Nacional de Derechos y Ciencias Sociales de Córdoba, http://www.acaderc.org.ar

- PICCON, Augusto "Testimonios con obligaciones pendientes", Revista de Estudios de Derecho Notarial y Registral, Universidad Blas Pascal Año $5 N^{\circ} 5$ (2018). 
- María Alejandra ASTUENA, Virginia BENFIELD, Gustavo A. DARCHUK, Roberto MIGNOLO, José María LORENZO, Mariano LOZANO, Pablo SUKAREVICIUS, Elsa ROSIN de ALLENDE y Luciana TORRES DUBECQ, "Incorporación de Documentación Habilitante Digital al Protocolo", trabajo presentado en las Jornadas Nacionales del Notariado, Bariloche 2018.

- VENTURA, Gabriel B, "Certificado Registral expedido con Firma Digital" Revista del Notariado N95, año 2017.

- FALBO Santiago y DI CASTELNOVO, Falbo "Nuevas Tecnologías Aplicadas a la Función Notarial”, Di Lalla Ediciones, Buenos Aires 2019

- PELOSI Carlos A., "Los Certificados Notariales", Revista del Notariado 716 de 1971

- BIBIANA, Luz Clara "Ley de Firma Digital Comentada”, Editorial Jurídica Nova Tesis, Rosario 2006

- CABULI, Ezequiel. "Las nuevas tecnologías en el proyecto del Código" - La Ley -)

T. 2013-)A

- CONSENTINO, M. \& Giralt Font, M. (2017) "La firma digital en el nuevo Código Civil y Comercial". Revista del Consejo Federal del Notariado Argentino.

- FALBO, Santiago. "Protocolo digital: nuevas tecnologías y función notarial: Otorgamiento del documento notarial digital y circulación electrónica del documento notarial”. págs. 19-)59. En: Revista Notarial. La Plata, Colegio de Escribanos de la Provincia de Buenos Aires, enero-) abril 2015, n. 979 / Revista notarial no 95, año 2017. Colegio de escribanos de la Provincia de Córdoba

- FARRES, Pablo: "Ley de firma digital comentada y concordada" -) Ed. Abeledo Perrot -) Bs. As. - 2005.

- DUMEYNIEU Natalia María Irene y ROBLEDO, Analía Alejandra, "El Notario en Digital", trabajo presentado en las Jorna trabajo presentado en las Jornadas Nacionales del Notariado, Bariloche 2018.

- FARRES, Pablo: “Firma Digital”, Ed. Lexis Nexis, Bs.As. 2005.

- FRASCHETTI, Alejandro: "La ley de firma digital y las presunciones de autoría e integridad" - La Ley

- GIRALT FONT, Martn J. "Certificación Notarial de Firma Digital”, en Revista Notarial, № 879

- GIRALT FONT, M. J. y Saenz, C. A. (2013, abril). Las nuevas tecnologías, la firma y el Notario. Noticias del Consejo Federal del Notariado Argentino. 49, 18-)28.

- MOISSET DE ESPANES, Luis y MARQUEZ, José F. "La formación del consentimiento en la contratación electrónica”, La Ley, 2004

- PONCE DE FAUSTINELLI, Marcia Isabel - "El Documento Electrónico" Revista Notarial del Colegio de Escribanos de Córdoba N72 del año 1996

- VENTURA Gabriel B. "Firma Digital - Análisis exegético de la Ley 25506/2001 (Ley 25.505 - Firma Digital. B.O. 14/12/2001) 
